\title{
Poliarterite nodosa: revisão de literatura a propósito de um caso clínico
}

\author{
Polyarteritis nodosa: literature review related to a case report \\ Otacilio Figueredo Silva Junior ${ }^{1}$, Eutília Andrade Medeiros Freire ${ }^{2}$, Francisco Chavier Bandeira ${ }^{3}$, \\ Rodrigo Rodrigues Cavalcante Leite ${ }^{4}$, Francisco Daniel Bezerra Amorim ${ }^{4}$, \\ Danilo Rodrigues Cavalcante Leite ${ }^{4}$, Uirá Luiz de Melo Sales Marmhoud Coury ${ }^{5}$
}

\section{Resumo}

A poliarterite nodosa é uma doença rara. Trata-se de uma vasculite sistêmica caracterizada pela presença de um processo inflamatório agudo e necrose fibrinoide das artérias de pequeno e médio calibre. O curso pode ser agudo ou crônico, com grande variabilidade de sinais e sintomas devido aos diversos órgãos que podem ser afetados, preferencialmente o sistema nervoso periférico, rins e pele. Os autores relatam o caso de um paciente com manifestações clínicas e evolução incomum.

Palavras-chave: Poliarterite nodosa, clínica, diagnóstico.

\section{Introdução}

A poliarterite nodosa (PAN) é uma vasculite necrosante sistêmica caracterizada pela presença de um processo inflamatório agudo e necrose fibrinoide das artérias de pequeno e médio calibre. É uma doença considerada rara, com uma prevalência na população geral de cerca de seis por 100.000 pessoas. É mais comum nos homens entre 40 e 60 anos, com uma proporção de cerca de 2:1 em relação às mulheres ${ }^{1}$.

O curso pode ser agudo ou crônico, com longos intervalos assintomáticos. Há grande variabilidade dos sinais e sintomas devido aos diversos órgãos que podem ser afetados, atingindo preferencialmente o sistema nervoso periférico, o rim, a pele, o aparelho digestivo, o coração e as articulações $^{2-5}$. Em mais de $70 \%$ dos doentes, a febre é a manifestação inicial. Artralgias ou artrite surgem em cerca de $50 \%$ dos casos, sendo a poliartrite assimétrica não deformante das grandes articulações das extremidades inferi-

\begin{abstract}
Polyarteritis nodosa is a rare disease, being a systemic vasculitis characterized by the presence of an acute inflammatory process and fibrinoid necrosis of small and medium-sized arteries. Its course may be acute or chronic, with large variability of signs and symptoms due to various organs that may be affected, mainly peripheral nervous system, kidneys, and skin. The authors report the case of a patient with unusual clinical manifestations and course.
\end{abstract}

Keywords: Polyarteritis nodosa, clinical features, diagnosis.

ores a mais comum. Na PAN, são frequentes as manifestações cutâneas, sendo as mais comuns: livedo reticularis, fenômeno de Raynaud e úlceras e alterações isquêmicas das extremidades dos dedos ${ }^{6-9}$. Sintomas sistêmicos, como a dor em vísceras e nos músculos esqueléticos, ocorrem devido ao declínio do suprimento arterial. É comum no quadro, a hipertensão arterial de início rápido. A doença pode progredir para uma insuficiência renal devido à vasculite.

A patogênese é ainda pouco conhecida, mas relacionada a mecanismos imunes ${ }^{10-12}$. Cerca de $30 \%$ dos pacientes com PAN possuem os antígenos de superfície HbSAg e Anti-Hbs do vírus da hepatite B no soro. O diagnóstico é histopatológico e baseia-se na demonstração das lesões vasculares características em biópsias de, por exemplo, pele ou músculo ${ }^{13,14}$.

Sem tratamento, a doença é fatal na maioria dos casos por insuficiência renal crônica ou complicações da hiper-

\footnotetext{
1. Professor adjunto, Universidade Federal da Paraíba (UFPB), João Pessoa, PB.

2. Professor adjunto, UFPB, João Pessoa, PB.

3. Cirurgião vascular. Professor assistente, UFPB, João Pessoa, PB.

4. Acadêmico de Medicina, UFPB, João Pessoa, PB

5. Médico Residente ( $2^{\circ}$ ano), Cirurgia Geral, Hospital Universitário Lauro Wanderley (HULW), João Pessoa, PB.

Não foram declarados conflitos de interesse associados à publicação deste artigo.

Artigo submetido em 01.06.09, aceito em 16.11.09.

J Vasc Bras. 2010;9(1):86-89.

Copyright (C 2010 by Sociedade Brasileira de Angiologia e de Cirurgia Vascular
} 
tensão. Terapia com corticosteroides e quimioterápicos como a ciclofosfamida resultam em sobrevida maior que 5 anos em $80 \%$ dos casos. O tratamento eficiente da hipertensão é fundamental para um prognóstico melhor.

\section{Relato de caso}

Paciente do sexo masculino, 28 anos, pardo, com história de surgimento de lesão enegrecida em quinto pododáctilo esquerdo aproximadamente 20 dias antes da consulta. Posteriormente, apareceram novas lesões enegrecidas em primeiro quirodáctilo direito, face interna dos antebraços, coxa esquerda e testículo esquerdo junto com uma dor forte, insidiosa e com sensação de peso no testículo afetado. Associadas a esses sintomas, apresentava febre e perda de peso de $5 \mathrm{~kg} \mathrm{em} 2$ meses e, havia 2 dias, queixava-se de dispneia. Tinha história pregressa de dores articulares associada a edema de caráter migratório que tinham se manifestado, primeiro, em tornozelos e, depois, em joelhos e punhos havia 2 anos. Nove meses após a investigação (trazia fatores antinucleares 1/1280 padrão pontilhado fino, fator reumatoide negativo e velocidade de hemossedimentação e proteína C-reativa elevadas) foi diagnosticado com artrite reumatoide e iniciou tratamento com prednisona e indometacina, com melhora do quadro até os sintomas atuais. À admissão, apresentava-se com estado geral comprometido, prostrado, taquidispneico moderado, afebril, normocorado, consciente e orientado, com lesões isquêmicas em quinto pododáctilo esquerdo e primeiro quirodáctilo direito, lesões ulceradas em face interna de antebraço direito, coxa direita, testículo e coxa esquerdos (Figura 1). À avaliação cardiovascular apresentava-se hipotenso $(70 \times 50 \mathrm{~mm} \mathrm{Hg})$.

Evoluiu com desconforto respiratório e foi encaminhado ao CTI. Não houve necessidade de uso de drogas vasoativas ou ventilação mecânica, permanecendo o paciente em uso de máscara de Venturi a 50\%. Os exames revelavam IRA e uma acidose metabólica (Tabela 1). Devido à gravidade do caso e estando o paciente com febre, foram iniciadas antibioticoterapia com meropenem e vancomicina e pulsoterapia com metilprednisolona. Exames revelaram clearence de $\mathrm{Cr}=49,5 \mathrm{~mL} / \mathrm{min}$, proteinúia de $24 \mathrm{~h}=528 \mathrm{mg} / 24 \mathrm{~h}$ e sumário de urina normal. O paciente apresentou melhora do quadro respiratório e das escórias nitrogenadas e, após pulsoterapia por 3 dias com hemoculturas e urocultura negativas, recebeu alta para a enfermaria.

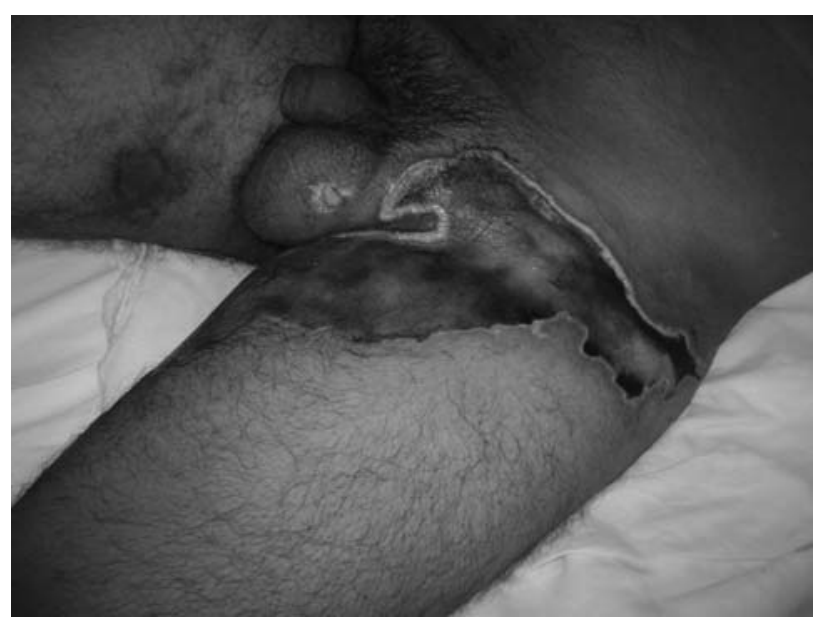

Figura 1 - Lesões ulceradas em coxa e testículo esquerdo

Houve melhora parcial das lesões isquêmicas em dedos, porém a lesão ulcerada de coxa apresentava bolhas que ao romperem expuseram o tecido subcutâneo, o que determinou que o paciente fosse mantido em antibioticoterapia. Houve surgimento de nódulos subcutâneos em região anterior das pernas (Figura 2). $\mathrm{O}$ anticorpo anticitoplasma de neutrófilos (ANCA) e as sorologias para hepatites $\mathrm{B}$ e $\mathrm{C}$ e HIV foram negativas. A tomografia de tórax mostrou infiltrado parenquimatoso intersticial alveolar nos lobos inferiores e discreto derrame pleural nos terços inferiores dos hemotórax. Realizou pulsoterapia com ciclofosfamida $1 \mathrm{~g}$. Evoluiu com melhora do quadro mantendo-se afebril, eupneico, com boa diurese, função renal normal e lesões em regressão. Recebeu alta hospitalar em uso de prednisona $60 \mathrm{mg} /$ dia e cuidados relativos à úlcera em coxa esquerda. Em seguida, retornou para desbrida-

Tabela 1 - Evolução laboratorial

\begin{tabular}{lcccc}
\hline $\begin{array}{l}\text { Dados } \\
\text { laboratoriais }\end{array}$ & $1^{\text {o dia }}$ & $2^{\circ}$ dia & $3^{\text {o dia }}$ & Unidades \\
\hline $\mathrm{Ur}$ & 77 & 108 & 38 & $\mathrm{mg} / \mathrm{dL}$ \\
$\mathrm{Cr}$ & 2,4 & 3,06 & 0,79 & $\mathrm{mg} / \mathrm{dL}$ \\
$\mathrm{K}$ & 4,9 & 5,2 & 4,5 & $\mathrm{mEq} / \mathrm{L}$ \\
$\mathrm{Hb}$ & 10,3 & 10 & 12,5 & $\mathrm{~g} / \mathrm{dL}$ \\
Leuco & 10.100 & 21.100 & 7.890 & $\times 10^{3} / \mathrm{mm}^{3}$ \\
Alb & 2,18 & 2,9 & - & $\mathrm{g} / \mathrm{dL}$ \\
VHS & 60 & - & 47 & $\mathrm{~mm}$ \\
PCR & 384 & - & 48 & $\mathrm{mg} / \mathrm{dL}$ \\
\hline
\end{tabular}

PCR = proteína C-reativa; VHS = velocidade de hemossedimentação. 


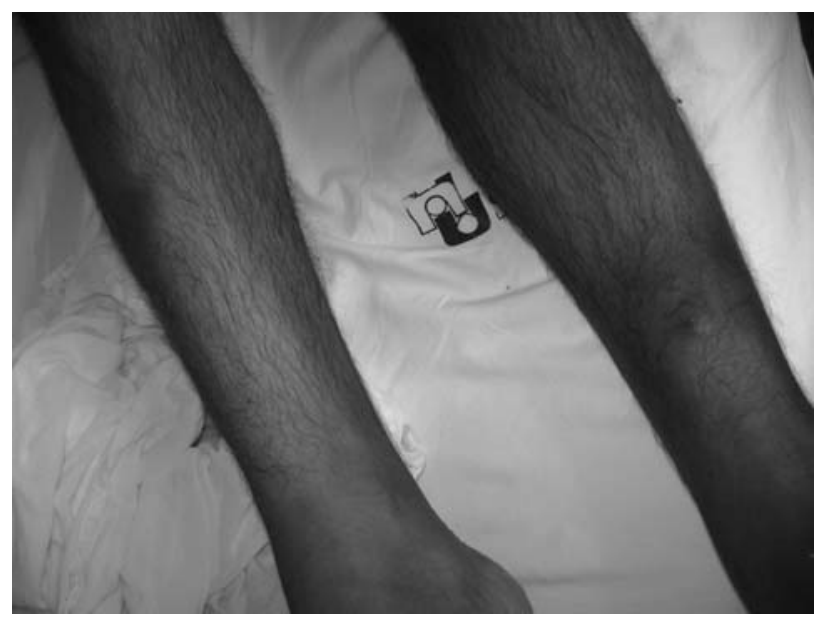

Figura 2 - Nódulos subcutâneos

mento cirúrgico das lesões (Figura 3) e posterior enxerto de pele na área acometida.

\section{Discussão}

A PAN é uma vasculite que acomete vasos de médio e pequeno calibre. É uma doença rara, de difícil diagnóstico, com manifestações clínicas e evolução variáveis, podendo ser confundida com outras vasculites. Acomete mais o sexo masculino, na faixa etária entre 40 e 60 anos. Sua incidência anual na população em geral oscila entre 4,6 e 9/100.000.

A PAN sistêmica normalmente inicia o quadro com fadiga, astenia, febre, mialgia e artralgia, seguindo-se por acometimentos específicos em órgãos como pele, nervos periféricos, trato digestivo e rins ${ }^{7-9,15}$.

O diagnóstico é clínico e histopatológico. Seguindo os 10 critérios do Colégio Americano de Reumatologia, a

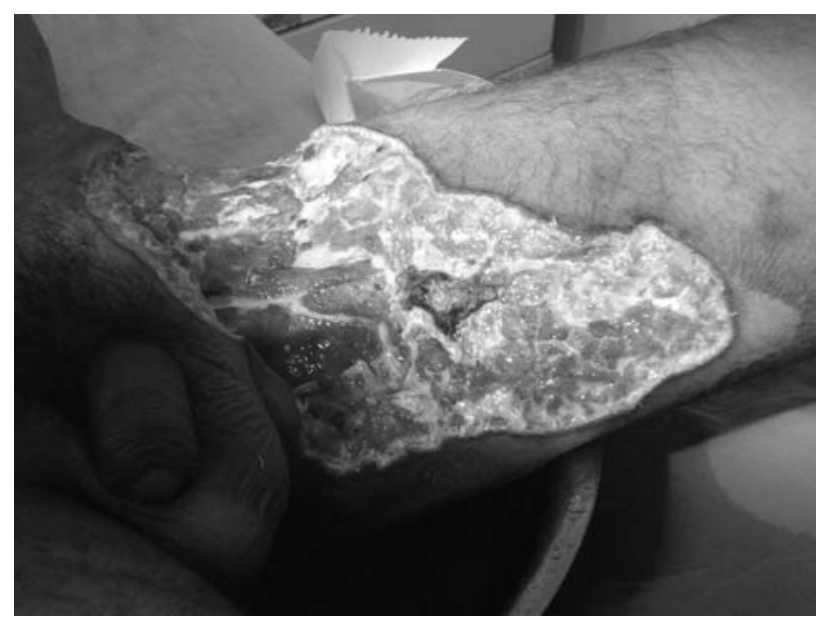

Figura 3 - Pós-desbridamento cirúrgico presença de três ou mais deles proporciona uma sensibilidade e especificidade alta para o diagnóstico de PAN. Ao exame histopatológico, observa-se inflamação necrosante das artérias de pequeno ou médio calibre sem glomerulonefrite ou vasculite nas arteríolas, capilares ou vênulas.

No presente artigo, relata-se um caso de um paciente jovem, com faixa etária incomum de acometimento da doença, iniciando a apresentação de maneira rara, com lesões isquêmicas no primeiro quirodáctilo direito, face interna dos antebraços, lesões ulceradas em coxa e testículo esquerdos, evoluindo para o surgimento de nódulos subcutâneos dolorosos e eritematosos em face anterior das pernas. A dor testicular apresentava início insidioso, gradativo, unilateral, no lado esquerdo, de forte intensidade e uma sensação de peso no testículo. Febre e mau estado geral acompanhavam o quadro clínico.

O diagnóstico baseou-se nas recomendações do Colégio Americano de Reumatologia pela presença dos seguintes critérios: perda ponderal superior a $4 \mathrm{~kg}$, dor testicular, mialgias, elevação de ureia e creatinina. No paciente, a biópsia da pele, músculo e rins, evidenciaram alterações histopatológicas compatíveis. Não houve presença de glomerulonefrite associada. Apesar de sua relevância ${ }^{16}$, não foi realizada angiografia pela falta de disponibilidade no serviço.

Foram solicitados fatores antinucleares, fator reumatóide e ANCA para exclusão de outras formas de vasculite ou enfermidades reumatológicas de maior gravidade, como o lúpus eritematoso ou a artrite reumatoide.

É importante fazer diagnóstico diferencial com a poliangiite microscópica (PAM). A PAM é uma doença muito semelhante à PAN do ponto de vista epidemiológico, clínico e histopatológico. Dela se diferencia, no entanto, por acometer apenas vasos de pequeno calibre, por não ocorrer na PAM a formação dos microaneurismas, pelo acometimento de ramos das artérias pulmonares que são classicamente poupados na PAN e por se apresentar comumente no acometimento renal mais como glomerulonefrite, raramente encontrada na PAN.

O tratamento proposto com corticoterapia e ciclofosfamida foi adequado ao caso, sendo preconizado na literatura, tendo boa evolução clínica o paciente com essa associação terapêutica ${ }^{17}$. 
O prognóstico da PAN com e sem tratamento varia. Tem-se observado, nos casos com terapia imposta, taxas de sobrevida em torno de $80 \%$ em 5 anos. No entanto, sem tratamento, as taxas de sobrevida foram de $50 \%$ no primeiro e de $13 \%$ no quinto ano de doença.

\section{Referências}

1. Neves S, Mota N, Dias M, Relvas M, Valente J. Poliarterite nodosa: a propósito de dois casos clínicos. Medicina Interna. 2001;8:144-9.

2. Costa, I. M. C., Nogueira, L. S. C. Poliarterite nodosa cutânea: relato de caso. An Bras Dermatol. 2006;81(5 Supl 3):S313-6.

3. Torpy JM, Lynm C, Glass RM. Vasculitis. J Am Med Assoc. 2007;298:706.

4. Hellmann DB, Schlott DW, Sisson SD, Cooper DS. Polyarteritis Nodosa. J Am Med Assoc. 2002;288:1632-9.

5. Nuñez GA, Espejo OM, Ibáñez RM, Torrelo FA, Gonzalez MI, Lopez RJ. Childhood cutaneous polyarteritis nodosa. An Esp Pediatr. 2001:54:506-9.

6. Requena L. Panniculitis. Part II. Mostly lobular panniculitis. J Am Acad Dermatol. 2001;45:325-64.

7. Dohmen K. Manifestations of cutaneous polyarteritis nodosa during interferon therapy for hepatitis $\mathrm{C}$ associated with primary biliary cirrosis. J Gastroenterol. 2000;35:789-93.

8. Lesavre P, Noël LH. Causes et mécanismes des vascularites: vascularites systémiques. Revue Prat. 2000;50:255-94.

9. Valente RM, Conn DL. Polyarteritis: polyarteritis nodosa and microscopic polyangiitis. In: Rheumatology, 2nd edition. Klippel SH, Dieppe PA, editors. Mosby. 2000;20:1-20.

10. Calabrese LH, Duns GF. Vasculitic syndromes. In: Stein JH, editor. Internal Medicine: CD. 2000, chap 195.

11. Rossi J, Macatti EF, Carvalhal SS. Poliarterite nodosa: considerações em torno de um caso com verificação à necropsia. Rev Cienc Med PUCCAMP. 1996;5:124-7.
12. Ancos AC, Rebollar JLM. Microscopic polyarteritis. An Med Interna. 1996;12:456-60.

13. Radu AS, Bueno C, Bonfá ES, Cossermelli W. Antineutrophil cytoplasmic antibodies in systemic vasculitis. Rev Hosp Clin Fac Med São Paulo. 1993;48:264-71.

14. Malcic I, Carin R. Polyarteritis nodosa: cutaneous or systemic form? Possible role of bacterial superantigens in the onset of systemic disease. Reumatizam. 1996;43:16-24.

15. Dias PJL, Shroeter AL, Winkelmann RK. Cutaneous periarteritis nodosa. immunofluorscence studies. Arch Dermatol. 1980;116:56-8.

16. El-Reshaid K, Kapoor M, El-Reshaid W, Madda J, Varro J. The spectrum of renal disease in polyarteritis nodosa in $\mathrm{Ku}-$ wait. Nephrol-Dial-Transplant 1997;12:1874-82.

17. Helmann D. Polyarteritis nodosa. The Johns Hopkins Vasculitis Center; 1998.

Correspondência:

Rodrigo Rodrigues Cavalcante Leite

Av. Epitácio Pessoa, 4885/902, Tambaú

CEP 58039-000 - João Pessoa, PB

rodrigomed71@hotmail.com

\section{Contribuições dos autores}

Concepção e desenho do estudo: OFS Junior

Análise e interpretação dos dados: RRCL, FCB

Coleta de dados: FDBA

Redação do artigo: RRCL

Revisão crítica do texto: EAMF

Aprovação final do artigo: OFS Junior, EAMF, FCB, RRCL, DRCL, FDBA, ULMSMC

Análise estatística: ULMSMC, DRCL

Responsabilidade geral pelo estudo: OFS Junior, EAMF

Informações sobre financiamento: OFS Junior

* Todos os autores leram e aprovaram a versão final submetida ao J Vasc Bras. 